\title{
Clinical Efficacy and Safety of Chinese Herbal Medicine Auxiliary Therapy for Childhood Cough Variant Asthma: A Systematic Review and Meta-analysis of 20 Randomized Controlled Trials
}

\author{
Ping Song ${ }^{1}$, Lingfeng Zeng ${ }^{1,2}$, Zhaohui Liang ${ }^{3}$, Qi Wang ${ }^{1,2}$ and Aihua $\mathrm{Ou}^{1}$
}

\begin{abstract}
This study aimed to evaluate the efficacy and safety of Chinese herbal medicine auxiliary therapy (CHMAT) in treating childhood cough variant asthma (CVA). A systematic literature review was conducted on RCTs that compared CHMAT, i.e., Chinese herbal medicine (CHM) plus pharmacotherapy (PT), versus the same PT alone in the treatment of CVA. All included trials were assessed for quality and risk bias and analyzed according to the criteria of the Cochrane Handbook based on the Review Manager 5.3 software program. Twenty studies were identified and the CHMAT group had a positive effect on the total effective rate and a lower recurrence rate compared with the control group. CHMAT may have positive effects on CVA, leading to better improvement in disorders of cough and asthma and less adverse effects. However, the methodology and reporting quality of current studies are generally low. Further studies should include larger sample sizes with a strict design to confirm these findings.
\end{abstract}

Key words: Chinese herbal medicine (CHM), childhood cough variant asthma (CVA), randomized controlled trials, systematic review, meta-analysis

(Intern Med 55: 2135-2143, 2016)

(DOI: 10.2169/internalmedicine.55.5546)

\section{Introduction}

Cough variant asthma (CVA) is a subtype of bronchial asthma characterized by episodes of cough, chronic cough and intractable cough, particularly at night $(1,2)$. CVA accounted for $24.0-33.3 \%$ of chronic cough cases, and children comprise $0.18 \%$ of the total incidence $(3,4)$. Pharmacotherapy (PT) consisting of glucocorticoids, antihistamine drugs or $\beta 2$ agonists is predominantly used in the treatment of CVA patients (5). However, the results are poor and considered to be largely due to contraindications, side effects or addiction. At present, Chinese herbal medicine (CHM) either used alone or integrated with conventional PT has been widely chosen for the treatment of CVA in China. In recent years, previous reports by Ge et al. (6), Zhang et al. (7), and Chen et al. (8) demonstrated systematic reviews on CHM for childhood CVA, which compared CHM versus conventional PT alone using Jadad scores for the quality of literature evaluation and the effective rate for the clinical curative effect evaluation. Thus, previous reports have lacked a relatively objective evaluation of the quantitative indicators. Therefore, a systematic literature review was conducted in the present study using randomized control trials (RCTs) that compared CHMAT, i.e., CHM plus conventional PT, versus the same PT alone in the treatment of childhood CVA. All included trials were assessed for quality and risk bias and analyzed according to the criteria of the Cochrane Handbook. The outcome measures included the total effective rate, recurrence rate, symptom outcome improvement of traditional Chinese medicine (TCM), the levels of lung function containing the forced expiratory volume in one second $\left(\mathrm{FEV}_{1}\right), \mathrm{FEV}_{\mathrm{I}} /$ forced vital capacity $(\mathrm{FVC})(\%)$, peak expiratory flow rate (PEFR), and PEFR (\%). Moreover, the cough

${ }^{1}$ The 2nd Affiliated Hospital of Guangzhou University of Chinese Medicine, China, ${ }^{2}$ Institute of Clinical Pharmacology, Guangzhou University of Chinese Medicine, China and ${ }^{3}$ School of Information Technology, York University, Canada

Received for publication May 1, 2015; Accepted for publication December 13, 2015

Correspondence to Dr. Aihua Ou,1347301175@qq.com,wqdme01@163.com 
sensitivity $\mathrm{LgC}_{5}$, total immunoglobulin $\mathrm{E}$ (T-IgE) and the levels of eosinophils (EOS) were included.

The objective of this review was to evaluate the evidence for efficacy of treatment using CHMAT versus the same PT in childhood CVA according to RCTs that used objective outcome measures and indices. Moreover, the study also aimed to assess the safety of the integrative treatments.

\section{Methods}

\section{Criteria for study inclusion in this review}

Types of studies: All RCTs without restrictions on language, blinding, or publication type were included.

Types of participants: National and international studies enrolling patients with childhood CVA as defined by the Chinese Medical Association or other well-recognized CVA diagnostic criteria were included. Patients between 0-14 years of age, of both sexes and of any ethnic group with diagnosed CVA were included. Patients with serious lung diseases, such as chronic obstructive pulmonary disease, lung cancer and tuberculosis, or mentally ill were excluded.

Types of interventions: Studies comparing oral CHMAT plus conventional PT versus the same conventional PT alone for childhood CVA, including any pharmaceutical dosage form such as decoction, capsule, particle, pill, or powder, were included.

Types of outcomes: The primary outcome was the total effective rate. Secondary outcomes included the symptom outcome improvement of TCM and the levels of lung function containing $\mathrm{FEV}_{1}, \mathrm{FEV}_{1} / \mathrm{FVC}(\%)$, PEFR and PEFR (\%). Moreover, the levels of $\mathrm{LgC}_{5}, \mathrm{~T}-\mathrm{IgE}$ and EOS were included. The Chinese medicine (CM) efficacy standards were defined as follows (9): Efficacy index $(n)=($ symptom score sum before treatment - symptom score sum after treatment)/symptom score sum before treatment $\times 100 \%$; (1)Clinical control: $\mathrm{n} \geq 90 \%$; (2) Markedly effective: $60 \% \leq \mathrm{n}<90 \%$; (3)Effective: $30 \% \leq \mathrm{n}<60 \%$; and (4) Ineffective: $\mathrm{n}<30 \%$. In additional, a safety evaluation was assessed using the Treatment Emergent Symptom Scale (TESS) and the incidence of treatmenteffect adverse events.

\section{Search methods for the identification of studies}

We used the following electronic databases to search all relevant studies: PubMed (1966 to December 2014), the Cochrane Central Register of Controlled Trials, EMBASE (1980 to December 2014), the Chinese Biomedicine Database (CBM) (1976 to December 2014), China National Knowledge Infrastructure (CNKI) (1979 to December 2014), and VIP (1989 to December 2014). All trials included were analyzed according to the criteria of the Cochrane Handbook. The Review Manager (RevMan) 5.3 software program was used for the data analysis. The following search terms were used: "childhood cough variant asthma," or "childhood cough type asthma" or "cough variant asthma in children" or "cough type asthma in children" AND "pharmacotherapy or traditional Chinese herbal" or "alternative medicine" AND "randomized or controlled or clinical research/study".

\section{Assessment of risk of bias in the included studies}

According to the recommendations in the Cochrane Handbook, the methodological qualities of trials were evaluated independently by two investigators using the assessment tool for risk of bias. The following checklists lie as follows: (1) Random sequence generation; (2)Allocation concealment; (3) Blinding of participants and personnel; (4)Blinding of outcome assessors; (5)Incomplete outcome data; and (6)Selective outcome reporting.

\section{Data collection and analysis}

Study selection: To verify the studies that met the inclusion criteria, we examined abstracts from the initial search independently. We telephone-interviewed the original authors of the Chinese articles to identify the randomization procedure and other methodological issues to ensure that the included studies were RCTs. If the required information was not available, then the articles were excluded.

Data extraction: The quality of studies that included randomization was assessed independently by two investigators (SP and ZLF) using a piloted data extraction form. There were no disagreements (see Table 1).

Data analysis: The Cochrane Collaboration's RevMan 5.3 software program was used for all data analyses. For dichotomous outcomes, the results were expressed as the odds risk (OR) with $95 \%$ confidence intervals (CI); for continuous outcomes, the data were expressed as the mean difference (MD) $95 \%$ CI. Heterogeneity was tested with $\mathrm{I}^{2}$. The $\mathrm{I}^{2}$ values of $50 \%$ or greater indicated a substantial level of heterogeneity, thus a random-effects model (REM) was used for data pooling. Otherwise, a fixed-effects model (FEM) was applied. In additional, funnel plots were conducted and checked for potential publication bias when nine or more studies reported the same outcome measure.

\section{Results}

\section{Results of the search}

An initial search identified 694 potentially relevant articles. Following the search and study selection process (Fig. 1), 20 (10-29) studies (1,590 participants) were included in this review. All studies were published in Chinese.

\section{Assessment of risk of bias}

See Table 2.

\section{Meta-analyses of the outcomes}

Comparison of the effective rate: A total of 19 trials (10-21, 23-29) reported the total effective rates with the fixed-effects meta-analysis demonstrating a significant difference in favor of the CHMAT group (OR 3.52, 95\%CI 2.574.82, p<0.00001) (Fig. 2). 
Table 1. Characteristics of the Included Studies.

\begin{tabular}{|c|c|c|c|c|c|c|c|}
\hline \multirow{2}{*}{ References } & \multicolumn{2}{|c|}{ No. of participants } & \multirow{2}{*}{ Baseline } & \multicolumn{2}{|c|}{ Intervention } & \multirow{2}{*}{$\begin{array}{c}\text { Course of } \\
\text { treatment }(w)\end{array}$} & \multirow{2}{*}{$\begin{array}{c}\text { Outcome } \\
\text { measures }\end{array}$} \\
\hline & Trial & Control & & Trial & Control & & \\
\hline 10 & 54 & 54 & Comparability & CHMAT & PT & 8 & (1) (3) \\
\hline 11 & 48 & 48 & Comparability & CHMAT & PT & 4 & (1)(3)(4) \\
\hline 12 & 40 & 40 & Comparability & CHMAT & PT & 4 & (1) (2) 8 \\
\hline 13 & 58 & 58 & Comparability & CHMAT & PT & 4 & (1)(3) 8 \\
\hline 14 & 27 & 23 & Comparability & CHMAT & PT & 4 & (1)(2) (3) (5) \\
\hline 15 & 40 & 40 & Comparability & CHMAT & PT & 6 & (1) (2) \\
\hline 16 & 18 & 18 & Comparability & CHMAT & PT & 4 & (1) (3) \\
\hline 17 & 30 & 30 & Comparability & CHMAT & PT & 6 & (1) (5) 7 \\
\hline 18 & 50 & 50 & Comparability & CHMAT & PT & 4 & (1) \\
\hline 19 & 30 & 30 & Comparability & CHMAT & PT & 4 & (1) \\
\hline 20 & 30 & 30 & Comparability & CHMAT & PT & 3 & (1) (3) \\
\hline 21 & 45 & 45 & Comparability & CHMAT & PT & 4 & (1) (3) \\
\hline 22 & 36 & 31 & Comparability & CHMAT & PT & 8 & (2) (3) 8 \\
\hline 23 & 60 & 60 & Comparability & CHMAT & PT & 4 & (1) (2) (6) (7) \\
\hline 24 & 30 & 30 & Comparability & CHMAT & PT & 4 & (1) (3) (6) \\
\hline 25 & 65 & 50 & Comparability & CHMAT & PT & 4 & (1) (2) (3) (4) \\
\hline 26 & 25 & 25 & Comparability & CHMAT & PT & 4 & (1) (4) \\
\hline 27 & 40 & 40 & Comparability & CHMAT & PT & 3 & (1)(2) (3) \\
\hline 28 & 40 & 40 & Comparability & CHMAT & PT & 6 & (1) 8 \\
\hline 29 & 42 & 40 & Comparability & CHMAT & $\mathrm{PT}$ & 8 & (1) (3) (4) 8 \\
\hline
\end{tabular}

Annotation: (1): Effective rate, (2): Recurrence rate, (3): Clinical symptom evaluation, (4): Lung function detection, (5): $\mathrm{LgC}_{5}$,

(6): IgE, (7): EOS, 8): Adverse events, CHMAT: Chinese herbal medicine adjuvant therapy, PT: Pharmacotherapy

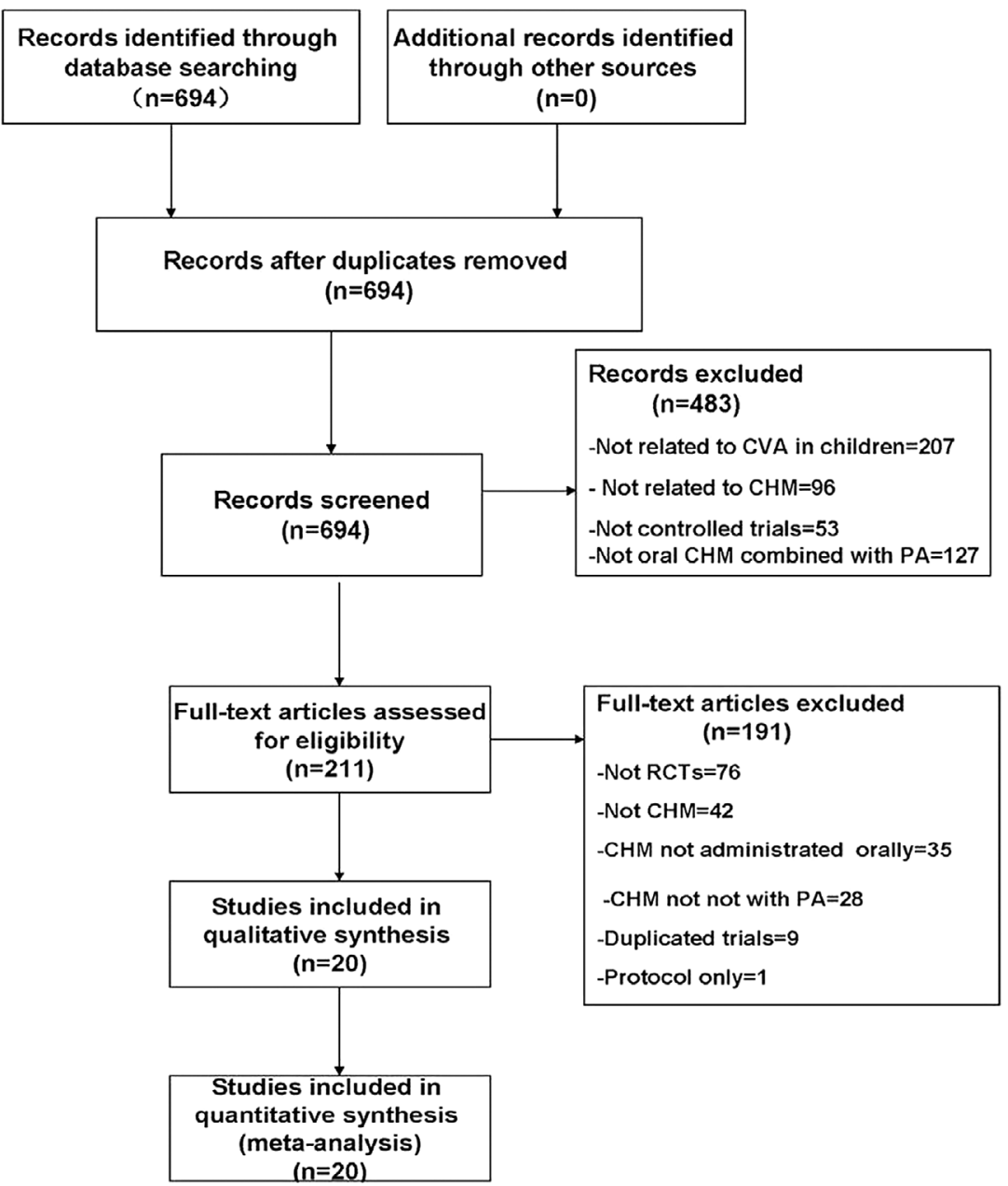

Figure 1. Flowchart of the search and study selection process. 
Table 2. Assessment of Risk of Bias for 20 Studies Based on the Cochrane Handbook.

\begin{tabular}{|c|c|c|c|c|c|c|}
\hline References & $\begin{array}{l}\text { Sequence } \\
\text { generation }\end{array}$ & $\begin{array}{l}\text { Allocation } \\
\text { concealment }\end{array}$ & $\begin{array}{l}\text { Blinding of } \\
\text { participants } \\
\text { and personnel }\end{array}$ & $\begin{array}{l}\text { Blinding of } \\
\text { outcome } \\
\text { Assessment }\end{array}$ & $\begin{array}{l}\text { Incomplete } \\
\text { outcome data }\end{array}$ & $\begin{array}{c}\text { Selective } \\
\text { outcome } \\
\text { reporting }\end{array}$ \\
\hline 10 & $\mathrm{~L}$ & $\bar{U}$ & $\mathrm{~L}$ & $\bar{U}$ & $\bar{U}$ & $\mathrm{~L}$ \\
\hline 11 & $\mathrm{U}$ & $\mathrm{U}$ & $\mathrm{U}$ & $\mathrm{U}$ & $\mathrm{U}$ & $\mathrm{H}$ \\
\hline 12 & $\mathrm{~L}$ & $\mathrm{U}$ & $\mathrm{U}$ & $\mathrm{U}$ & $\mathrm{L}$ & $\mathrm{U}$ \\
\hline 13 & $\mathrm{~L}$ & $\mathrm{~L}$ & $\mathrm{U}$ & $\mathrm{U}$ & $\mathrm{L}$ & $\mathrm{U}$ \\
\hline 14 & $\mathrm{U}$ & $\mathrm{U}$ & $\mathrm{U}$ & $\mathrm{U}$ & $\mathrm{L}$ & $\mathrm{L}$ \\
\hline 15 & $\mathrm{U}$ & $\mathrm{U}$ & $\mathrm{U}$ & $\mathrm{U}$ & $\mathrm{L}$ & $\mathrm{L}$ \\
\hline 16 & $\mathrm{U}$ & $\mathrm{U}$ & $\mathrm{U}$ & $\mathrm{U}$ & $\mathrm{H}$ & $\mathrm{L}$ \\
\hline 17 & $\mathrm{U}$ & $\mathrm{U}$ & $\mathrm{U}$ & $\mathrm{U}$ & $\mathrm{L}$ & $\mathrm{L}$ \\
\hline 18 & $\mathrm{U}$ & $\mathrm{U}$ & $\mathrm{U}$ & $\mathrm{U}$ & $\mathrm{L}$ & $\mathrm{U}$ \\
\hline 19 & $\mathrm{U}$ & $\mathrm{U}$ & $\mathrm{U}$ & $\mathrm{U}$ & $\mathrm{U}$ & $\mathrm{L}$ \\
\hline 20 & $\mathrm{U}$ & $\mathrm{U}$ & $\mathrm{U}$ & $\mathrm{U}$ & $\mathrm{L}$ & $\mathrm{L}$ \\
\hline 21 & $\mathrm{U}$ & $\mathrm{U}$ & $\mathrm{U}$ & $\mathrm{U}$ & $\mathrm{L}$ & $\mathrm{L}$ \\
\hline 22 & $\mathrm{U}$ & $\mathrm{U}$ & $\mathrm{U}$ & $\mathrm{U}$ & $\mathrm{L}$ & $\mathrm{L}$ \\
\hline 23 & $\mathrm{U}$ & $\mathrm{U}$ & $\mathrm{U}$ & $\mathrm{U}$ & $\mathrm{L}$ & $\mathrm{U}$ \\
\hline 24 & $\mathrm{U}$ & $\mathrm{U}$ & $\mathrm{U}$ & $\mathrm{U}$ & $\mathrm{L}$ & $\mathrm{L}$ \\
\hline 25 & $\mathrm{~L}$ & $\mathrm{U}$ & $\mathrm{U}$ & $\mathrm{U}$ & $\mathrm{U}$ & $\mathrm{L}$ \\
\hline 26 & $\mathrm{U}$ & $\mathrm{U}$ & $\mathrm{U}$ & $\mathrm{U}$ & $\mathrm{L}$ & $\mathrm{L}$ \\
\hline 27 & $\mathrm{U}$ & $\mathrm{U}$ & $\mathrm{U}$ & $\mathrm{U}$ & $\mathrm{L}$ & $\mathrm{L}$ \\
\hline 28 & $\mathrm{U}$ & $\mathrm{U}$ & $\mathrm{U}$ & $\mathrm{U}$ & $\mathrm{L}$ & $\mathrm{L}$ \\
\hline 29 & $\mathrm{~L}$ & $\mathrm{U}$ & $\mathrm{U}$ & $\mathrm{U}$ & $\mathrm{L}$ & $\mathrm{L}$ \\
\hline
\end{tabular}

Annotation: Risk of bias judgments: L: Low risk, U: Unclear risk, H: High risk

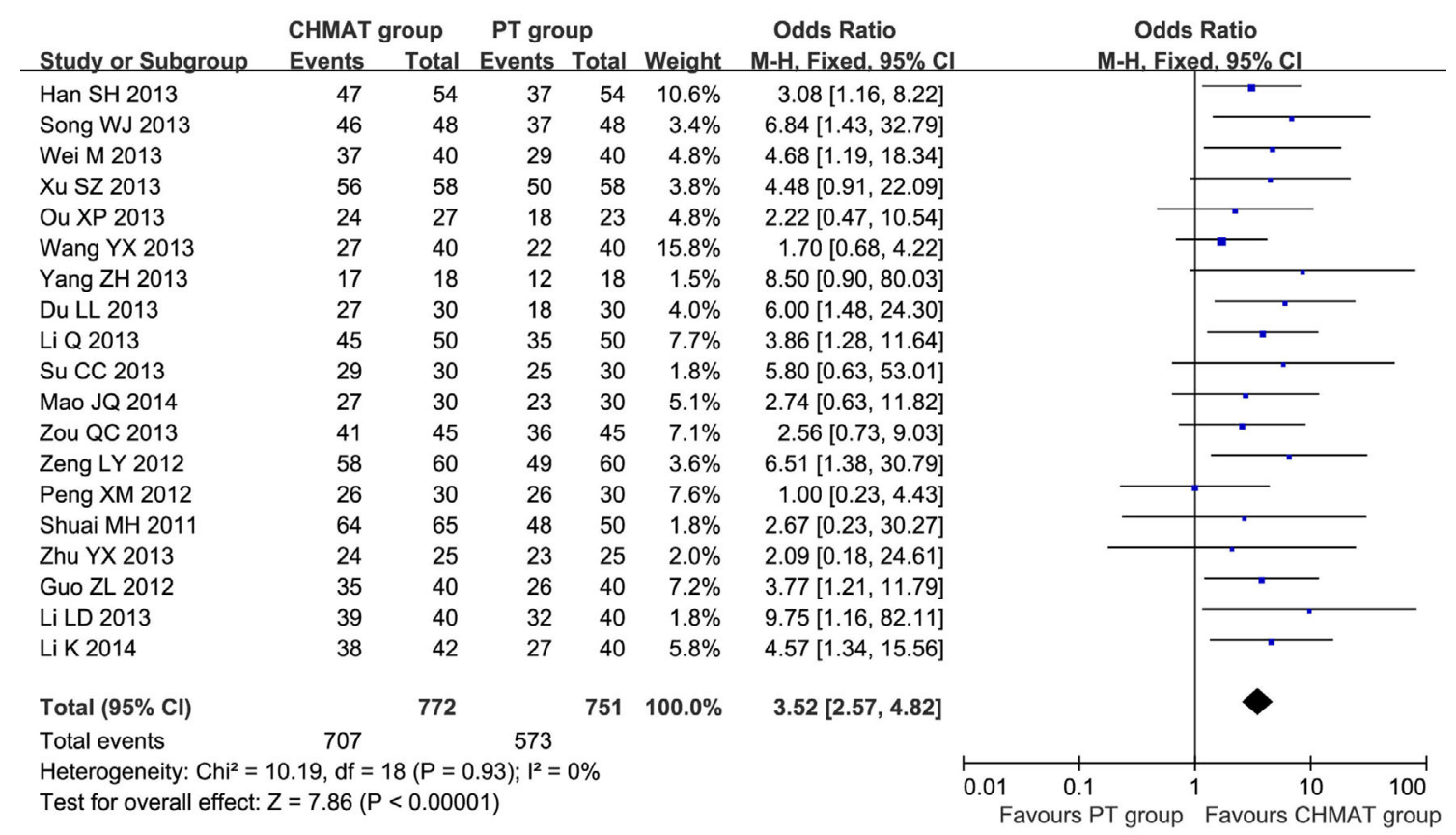

Figure 2. Meta-analysis of treatment effect of CHMAT group vs. the control group on effective rate.

Publication bias: Potential publication bias was determined by a funnel plot analysis of the 19 studies comparing the effective rate of CHMAT versus PT. A significant asymmetry was observed (Fig. 3), which indicated that trials of low quality were included and the existence of potential publication bias.

Comparison of the success withdrawal rate: Seven trials $(12,14,15,22,23,25,27)$ reported the success withdrawal rate, i.e., lower recurrence rate, with the fixed-effects meta-analysis demonstrating a significant difference in favor of the CHMAT group (OR 4.18, 95\%CI 2.57-6.80, $\mathrm{p}<$ 0.00001) (Fig. 4).

Comparison of the symptom outcome improvement of

\section{TCMnone}

Time of cough symptom relief: A total of 9 trials (10, $11,13,16,21,22,24,25,27)$ reported the time of cough symptom relief with the random-effects meta-analysis demonstrating a significant difference in favor of the CHMAT group $[\mathrm{MD}=-2.67, \quad 95 \% \mathrm{CI} \quad(-3.19,-2.16), \quad \mathrm{p}<0.00001]$ (Fig. 5). 


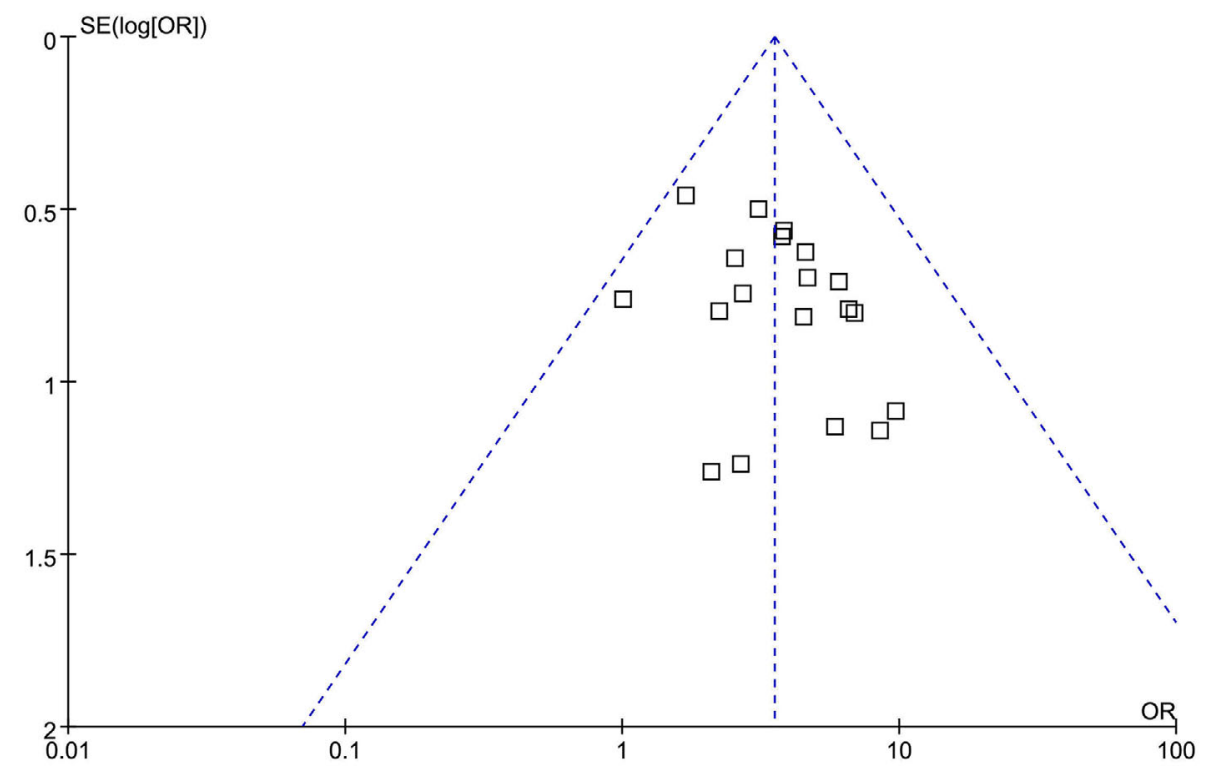

Figure 3. Funnel plot. Annotation: Comparison=CHMAT group vs. the control group; outcome=effective rate.

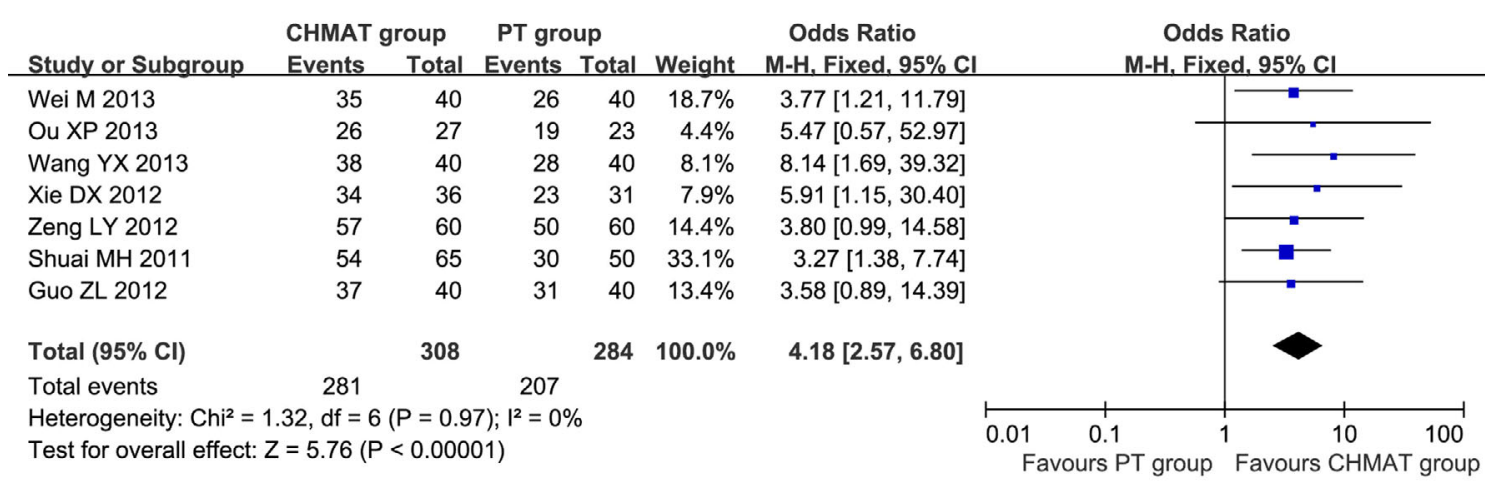

Figure 4. Meta-analysis of treatment effect of CHMAT group vs. the control group on success withdrawal rate.

Time of cough symptom removal: Seven trials $(10,13$, $16,21,22,24,25)$ reported the time of cough symptom removal with the random-effects meta-analysis demonstrating a significant difference in favor of the CHMAT group [MD=-2.62, 95\% CI (-3.76, -1.49), $\mathrm{p}<0.00001]$ (Fig. 5).

Time of asthma symptom removal: Two trials $(10,11)$ reported the time of asthma symptom removal with the fixed-effects meta-analysis demonstrating a significant difference in favor of the CHMAT group [MD $=-2.49$, 95\% CI $(-2.95,-2.03)], \mathrm{p}<0.00001$ (Fig. 5).

Time of disappearance of wheezing: Two trials $(10,11)$ reported the time of disappearance of wheezing with the fixed-effects meta-analysis demonstrating a significant difference in favor of the CHMAT group [MD $=-2.85$, 95\%CI $(-3.40,-2.31), \mathrm{p}<0.00001]$ (Fig. 5).

Total score of CM syndrome: Three trials $(14,20,29)$ reported the total score of $\mathrm{CM}$ syndrome with the fixedeffects meta-analysis demonstrating a significant difference in favor of the CHMAT group [MD=-1.28, 95\%CI $(-1.55$, -1.00 ), $\mathrm{p}<0.00001$ ] (Fig. 5).
Comparison of the levels of lung function: Regarding the levels of lung function, the CHMAT group showed better effects in the indices of $\mathrm{FEV}_{1}[\mathrm{MD}=0.25,95 \% \mathrm{CI}(0.12$, $0.38), \mathrm{p}=0.0002], \mathrm{FEV}_{1} / \mathrm{FVC}(\%)[\mathrm{MD}=11.72,95 \% \mathrm{CI}(5.37$, 18.08), $\mathrm{p}=0.0003$ ], PEFR [MD $=1.12,95 \% \mathrm{CI}(0.69,1.56), \mathrm{p}$ $<0.00001]$, and PEFR (\%) [MD=-5.00, 95\%CI (-9.49, $-0.52), \mathrm{p}=0.03]$.

Comparison of $\mathbf{F E V}_{\mathbf{1}}(\mathbf{L})$ : Two trials $(11,26)$ reported the index of $\mathrm{FEV}_{1}$ with the fixed-effects meta-analysis demonstrated a significant difference in favor of the CHMAT group [MD $=0.25,95 \% \mathrm{CI}(0.12,0.38), \mathrm{p}=0.0002]$ (Fig. 6).

Comparison of $\mathbf{F E V}_{\mathbf{1}} / \mathbf{F V C}(\%)$ : Two trials $(11,26)$ reported the index of $\mathrm{FEV}_{1} / \mathrm{FVC}(\%)$ with the random-effects meta-analysis demonstrating a significant difference in favor of the CHMAT group [MD=11.72, 95\% CI $(5.37,18.08, \mathrm{p}=$ 0.0003)] (Fig. 6).

Comparison of PEFR (L): Two trials $(25,26)$ reported the index of PEFR with the fixed-effects meta-analysis demonstrating a significant difference in favor of the CHMAT group [MD=1.12, 95\% CI (0.69-1.56), $\mathrm{p}<0.00001]$ (Fig. 6). 
(A)

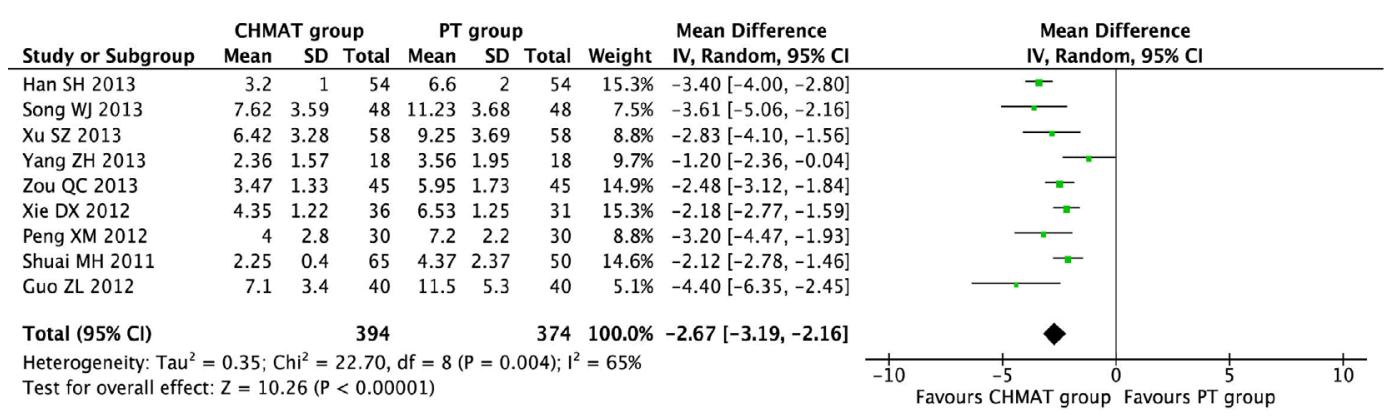

(B)

\begin{tabular}{|c|c|c|c|c|c|c|c|c|c|c|c|}
\hline \multirow[b]{2}{*}{ Study or Subgroup } & \multicolumn{3}{|c|}{ CHMAT group } & \multicolumn{3}{|c|}{ PT group } & \multirow[b]{2}{*}{ Weight } & \multirow{2}{*}{$\begin{array}{l}\text { Mean Difference } \\
\text { IV, Random, 95\% CI }\end{array}$} & \multirow{2}{*}{\multicolumn{3}{|c|}{$\begin{array}{c}\text { Mean Difference } \\
\text { IV, Random, } 95 \% \mathrm{CI}\end{array}$}} \\
\hline & Mean & SD & Total & Mean & SD & Total & & & & & \\
\hline Han SH 2013 & 7.5 & 3 & 54 & 11 & 4 & 54 & $14.0 \%$ & $-3.50[-4.83,-2.17]$ & —- & & \\
\hline Xu SZ 2013 & 10.35 & 4.34 & 58 & 14.67 & 4.71 & 58 & $12.7 \%$ & $-4.32[-5.97,-2.67]$ & & & \\
\hline Yang ZH 2013 & 6.71 & 2.01 & 18 & 9.56 & 3.13 & 18 & $12.4 \%$ & $-2.85[-4.57,-1.13]$ & & & \\
\hline Zou QC 2013 & 7.68 & 2.63 & 45 & 11.29 & 3.71 & 45 & $14.0 \%$ & $-3.61[-4.94,-2.28]$ & - & & \\
\hline Xie DX 2012 & 7.37 & 1.87 & 36 & 7.31 & 1.96 & 31 & $15.6 \%$ & $0.06[-0.86,0.98]$ & & 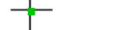 & \\
\hline Peng XM 2012 & 5.35 & 2.8 & 30 & 9 & 2.6 & 30 & $13.9 \%$ & $-3.65[-5.02,-2.28]$ & - & & \\
\hline Shuai MH 2011 & 2.4 & 0.4 & 65 & 3.7 & 0.4 & 50 & $17.3 \%$ & $-1.30[-1.45,-1.15]$ & - & 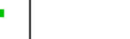 & \\
\hline Total $(95 \% \mathrm{CI})$ & & & 306 & & & 286 & $100.0 \%$ & $-2.62[-3.76,-1.49]$ & & & \\
\hline $\begin{array}{l}\text { Heterogeneity: Tau }{ }^{2} \\
\text { Test for overall effect }\end{array}$ & .94 & $\begin{array}{l}h^{2}= \\
2(P\end{array}$ & $\begin{array}{l}56.66, d \\
0.0000\end{array}$ & $\begin{array}{l}\mathrm{df}=6 \\
01)\end{array}$ & & 0001); & $I^{2}=89 \%$ & & 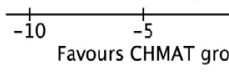 & oup Favours PT & $\begin{array}{l}5 \\
5 \text { group }\end{array}$ \\
\hline
\end{tabular}

(C)

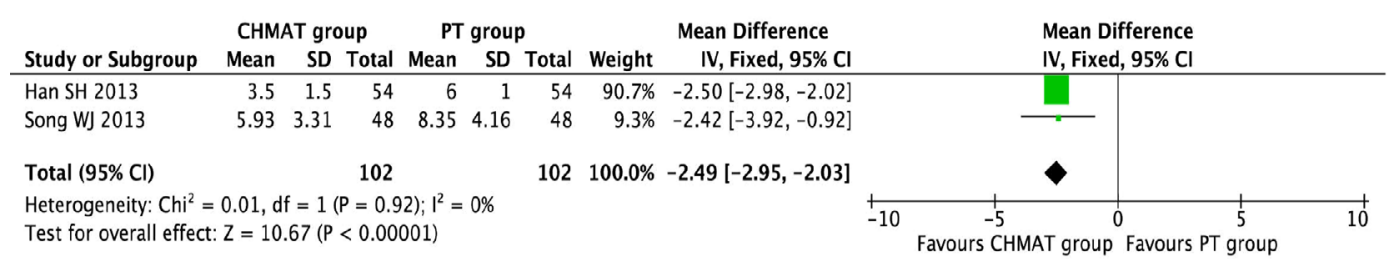

(D)

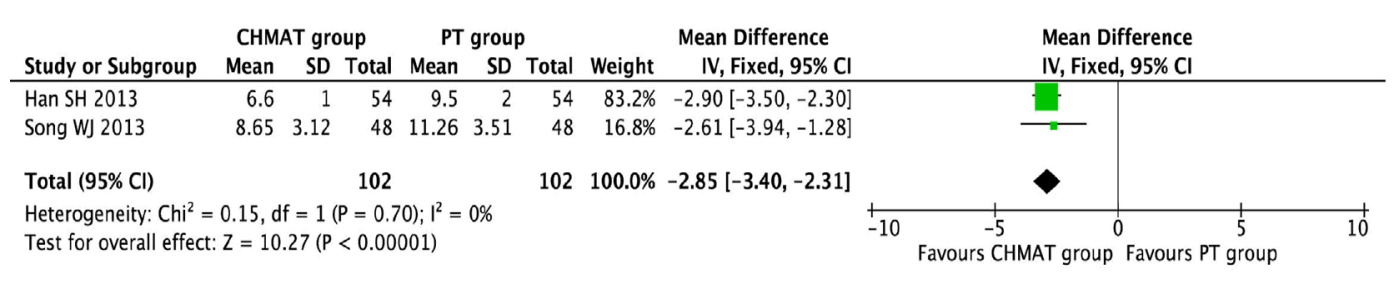

(E)

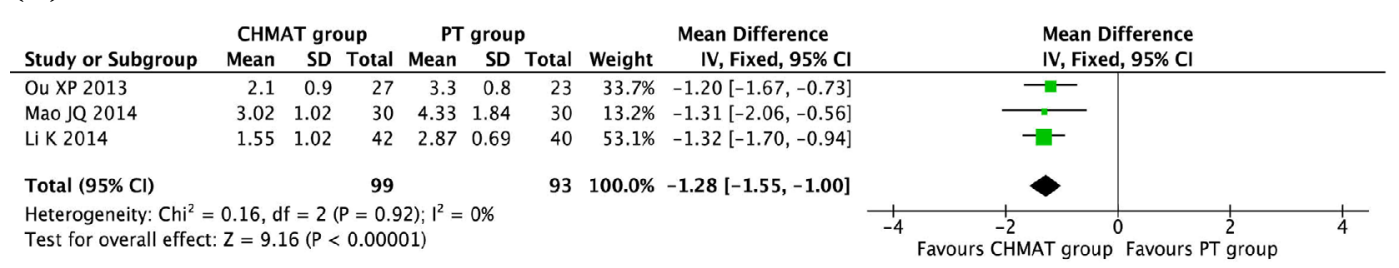

Figure 5. Meta-analysis of treatment effect of CHMAT group vs. the control group on symptom outcome improvement: (A) Time of cough symptom relieving. (B) Time of cough symptom removal. (C) Time of asthma symptom removal. (D) Time of disappearance of wheezing. (E) Total score of CM syndrome.

Comparison of PEFR (\%): Two trials $(25,26)$ reported the index of PEFR (\%) with the random-effects metaanalysis demonstrating a significant difference in favor of the CHMAT group $[\mathrm{MD}=-5.00,95 \% \mathrm{CI}(-9.49,-0.52), \mathrm{p}=$ 0.003] (Fig. 6).
Comparison of cough sensitivity $\mathrm{LgC}_{5}$ : Two trials $(14,17)$ reported the levels of $\mathrm{LgC}_{5}$ with the randomeffects meta-analysis demonstrating a significant difference in favor of the CHMAT group $[\mathrm{MD}=0.66$, 95\% CI $(0.18$, 1.14), $\mathrm{p}=0.007$ ] (Fig. 7). 
(A)

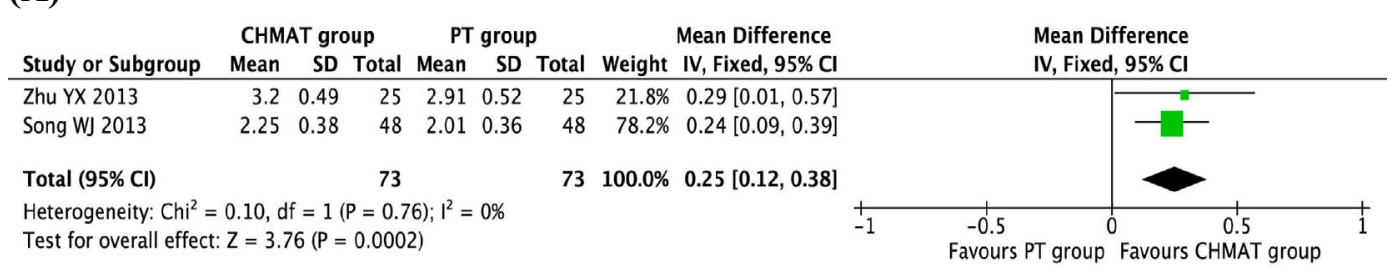

(B)

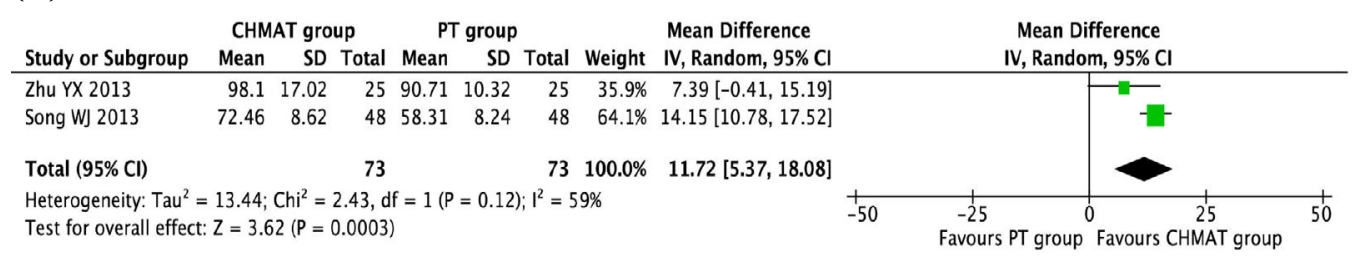

(C)

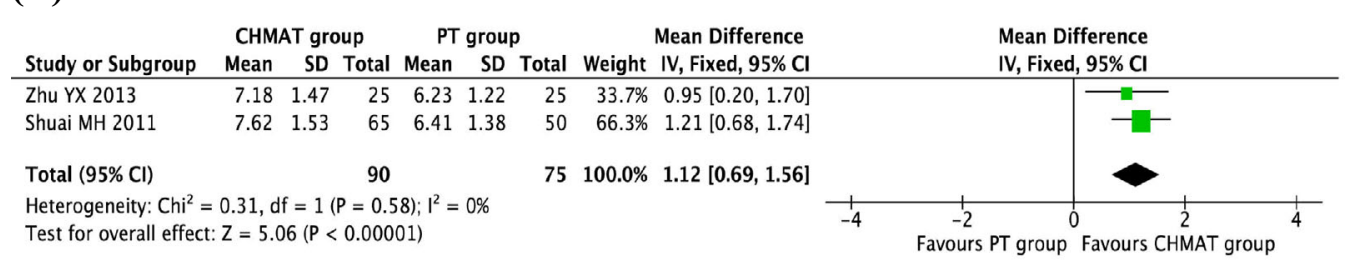

(D)

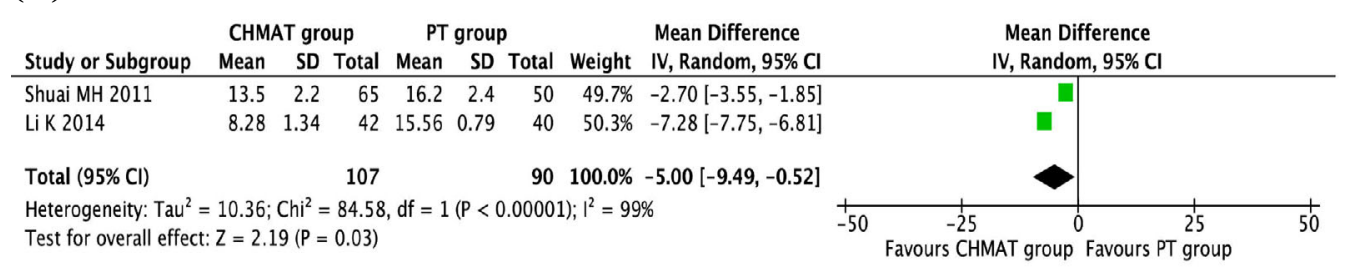

Figure 6. Meta-analysis of treatment effect of CHMAT group vs. the control group on Lung function detection changes: (A) Comparison of FEV 1 (L). (B) Comparison of FEV $1 / F_{1}$ (\%). (C) Comparison of PEFR (L). (D) Comparison of PEFR (\%).

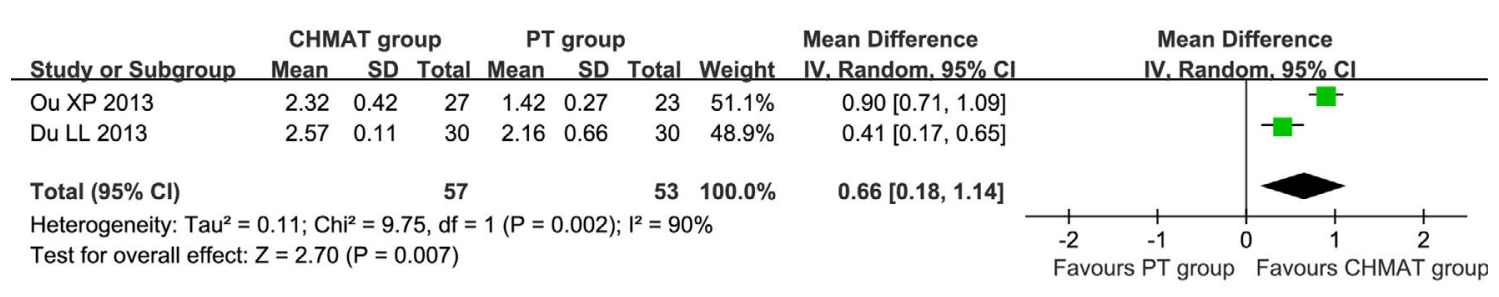

Figure 7. Meta-analysis of treatment effect of CHMAT group vs. the control group on cough sensitivity $\mathrm{LgC}_{5}$ changes.

Comparison of T-IgE: Two trials $(23,24)$ reported the levels of T-IgE with the fixed-effects meta-analysis demonstrating a significant difference in favor of the CHMAT group [MD=-56.67, 95\%CI $\quad(-83.01, \quad-30.34), \quad \mathrm{p}<0.0001]$ (Fig. 8).

Comparison of EOS: Two trials $(17,23)$ reported the levels of EOS with the fixed-effects meta-analysis demonstrating a significant difference in favor of the CHMAT group $[\mathrm{MD}=-0.19, \quad 95 \% \mathrm{CI} \quad(-0.26, \quad-0.12), \quad \mathrm{p}<0.00001]$ (Fig. 9).

\section{Safety evaluation}

Adverse events were observed in five studies (12, 13, 22, $28,29)$. No studies used the TESS score, but merely reported the number of adverse reactions and specific symptoms. For the CHMAT group, one trial (12) reported that 2 cases had palpitation and 1 case had tiredness; another (13) reported that 1 case had nasopharyngeal dryness; another (28) reported that 1 case had hoarseness; and the last (29) reported that 1 case had nausea. For the PT group, 


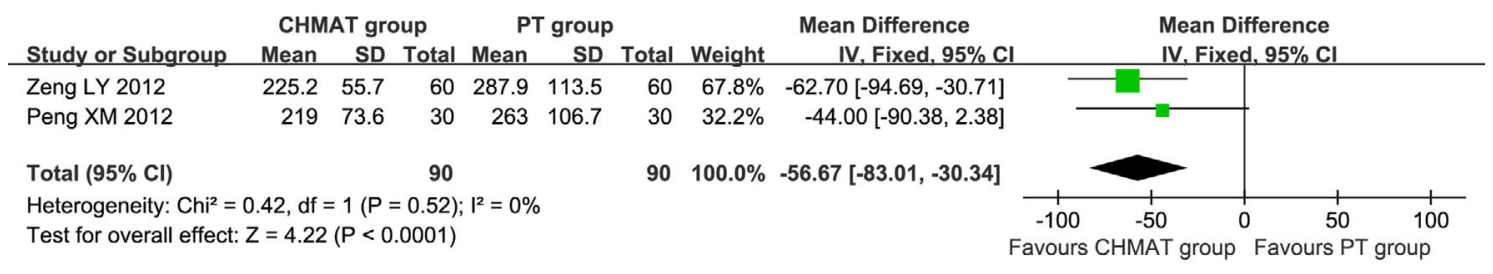

Figure 8. Meta-analysis of treatment effect of CHMAT group vs. the control group on T-IgE changes.

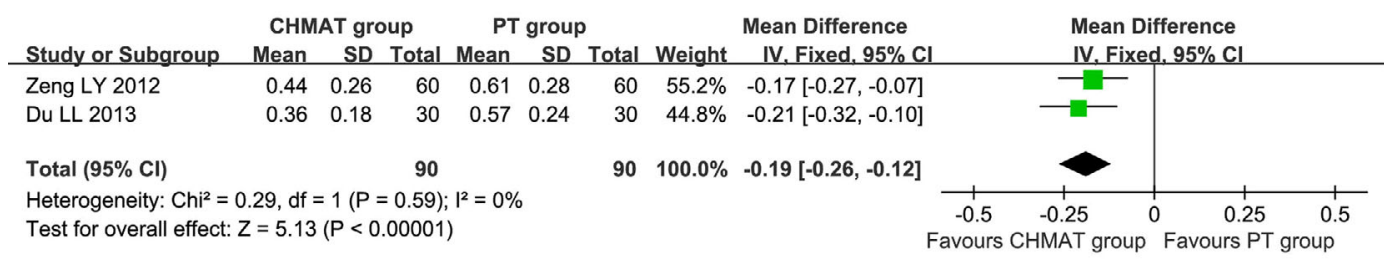

Figure 9. Meta-analysis of treatment effect of CHMAT group vs. the control group on EOS changes.

one trial (12) reported that 12 cases had palpitation, 14 cases had nausea and vomiting, 7 cases had hoarseness, 3 cases had tiredness and 2 cases had tremor; another (13) reported that 2 cases had tongue numbness, 1 case had dry eyes and 1 case had nasopharyngeal dryness; another (22) reported that 1 case had abdominal pain, 1 case had vomiting, 1 case had restlessness and 1 case had drowsiness; another (28) reported that 5 cases had hoarseness, 12 cases had palpitation, 11 cases had fibrillation, and 16 cases had nausea and vomiting; and the last (29) reported that 3 cases had nausea and 2 cases had palpitation.

\section{Discussion}

\section{Summary of evidence}

A total of 20 RCTs (10-29) involving 1,590 participants were included in this review and compared CHMAT with PT. The main findings of the present study were that there could be an additive benefit from CHMAT in terms of improving the indices in CVA patients. However, due to potential methodological deficits, e.g., limited number and small sample size of the included studies, the potential benefits of CHMAT in the treatment of CVA could not be fully confirmed according to the present evidence, and recommendations for clinical practice should be cautious.

The CHMAT group had a positive effect on the total effective rate compared with the control group. After treatment, the states of CVA were also improved in the CHMAT group compared with the control group in the following indices: time of cough symptom relief, time of cough symptom removal, time of asthma symptom removal, the time of disappearance of wheezing, and the total score of CM syndrome. Regarding the levels of lung function, the CHMAT group showed better effects in the indices of $\mathrm{FEV}_{1}, \mathrm{FEV}_{1} /$ FVC (\%), PEFR and PEFR (\%). Moreover, the CHMAT group can better improve the $\mathrm{LgC}_{5}$ and lower the levels of T-IgE and EOS. No serious or frequently occurring adverse effects were reported between the two groups.

\section{Limitations of the review}

These promising results should be interpreted with caution for the following reasons. The methodological deficits identified in the studies included few or no details regarding the generation process for the random sequence and allocation concealment. Thus, it remained unclear whether randomization or allocation concealment was effectively conducted in the studies. Inadequate blinding also contributed to overestimation effect in the trial group. None of the studies used identical placebos for the blinding operations. Therefore, these methodological deficits may have influenced the results of the present study. In additional, language bias and overemphasizing of positive effects due to publication bias may be another limitation of this review. The studies included only those written in Chinese and all research was conducted in China. There was a high compliance from the participants, who expected benefits from CHM. Thus, bias in the performance or in the measurement may have also existed due to the abovementioned factors.

\section{Conclusion}

The meta-analysis results indicated that the oral administration of CHMAT appeared to be effective for treating childhood CVA. CHMAT may have positive effects on CVA, leading to better improvement in disorders of cough and asthma and less adverse effects. However, the methodology and reporting quality of current studies are generally low. Further studies should include larger sample sizes with a strict design to confirm these findings.

The authors state that they have no Conflict of Interest (COI). 


\section{Financial Support}

This work was supported by the Natural Science Foundation of China (under grant No. 61105053), the Cultivation Project for Excellent Doctoral Dissertation of Guangdong Province (No. A1AFD015141Z10504), the Characteristic Key Discipline Construction Fund of Chinese Internal Medicine of Guangzhou University of Chinese Medicine and the South China Chinese Medicine Collaborative Innovation Center (No. A1-AFD01514A05). work.

Ping Song and Lingfeng Zeng contributed equally to this

\section{References}

1. Fujimura M. Pathophysiology, diagnosis and treatment of cough variant asthma. Rinsho Byori (The Official Journal of Japanese Society of Laboratory Medicine) 62: 464-470, 2014 (in Japanese).

2. Hekking PP, Bel EH. Developing and emerging clinical asthma phenotypes. J Allergy Clin Immunol Pract 2: 671-680, 2014.

3. Respiratory Disease Group, Pediatric Committee of Shanghai Medical Association. Epidemiological survey of asthma in children aged 0-14 years in seven districts of Shanghai. Chin J Pediatr 52: 17-22, 2014 (in Chinese, Abstract in English).

4. Liu CH, Shao MJ, Wang Q, et al. Epidemiological survey of children asthma prevalence in Beijing urban area. Chin J Pediatr 93: 574-578, 2013 (in Chinese, Abstract in English).

5. Tagaya E, Kondo M, Kirishi S, Kawagoe M, Kubota N, Tamaoki J. Effects of regular treatment with combination of salmeterol/fluticasone propionate and salmeterol alone in cough variant asthma. J Asthma 52: 512-518, 2015.

6. Ge ZY, Tong J, Lu FG. The meta-analysis of effects of traditional Chinese medicine on cough variant asthma in children. J Tradit Chin Med Univ Hunan 33: 104-108, 2013.

7. Zhang TH, Li XJ, Zhang S, et al. The systematic review of Chinese herbal medicine on childhood coughing variant asthma of randomized controlled trials. J Inform Tradit Chin Med 16: 97100, 2009.

8. Chen XW, Zhou Y, Zhong D, et al. Evaluation of literature quality of traditional Chinese medicine for cough variant asthma in children. J Emerg Tradit Chin Med 22: 1291-1292, 2013.

9. Miao Q, Wei PC, Fan MR, et al. Clinical study on treatment of cough variant asthma by Chinese medicine. Chin J Integr Med 19: 539-545, 2013.

10. Han SH. Clinical observation Suhuang-cough capsule in the treatment of children with cough variant asthma. J Clin Pulm Med 18: 1254-1255, 2013.

11. Song WJ, Chen B. Curative effects on combined traditional Chinese and western medicine treatment for 48 cases of childhood cough variant asthma. Med Innov China 10: 4-7, 2013.

12. Wei M. Clinical research on treating childhood cough variant asthma with the desensitization Dingchuan decoction of Wang-shi.
Clin J Chin Med 5: 17-19, 2013.

13. Xu SZ. The clinical effect of variant Xiao-qinglong decoction on cough variant asthma in children. J Clin Exp Med 12: 1050-1051, 2013.

14. Ou XP, Wu F, Gu Y, et al. Clinical observation of the effect of salmeterol/fluticasone and Suhuang cough-relieving capsule in the treatment of 50 children with cough variant asthma. J Clin Pulm Med 18: 257-258, 2013.

15. Wang YX. Clinical observation on treating cough variant asthma in children in the integrative medicine. Clin J Chin Med 5: 79-80, 2013.

16. Yang ZH, Yang WH, Shen YP. Clinical observation on treatment of childhood coughing variant asthma with integrative medicine. Chin J Health Birth Child Care 19: 559-561, 2013.

17. Du LL. Clinical study on Zhisou powder combined with Montelukast sodium tablets in the treatment of childhood coughing variant asthma. Zhejiang J Integr Tradit Chin Western Med 23: 932-933, 2013.

18. Li Q. Therapeutic efficacy of montelukast and astragalus on children cough variant asthma. Jilin Med J 34: 4214-4215, 2013.

19. Su CC. Clinical observation on children coughing variant asthma treated with Jiangqi zhike mianjian particles. Clin Med 33: 120$121,2013$.

20. Mao JQ. 30 cases of children coughing variant asthma treated by integrative medicine. Jiangsu J Tradit Chin Med 46: 36-37, 2014.

21. Zou QC. Clinical study on children coughing variant asthma treated with Ziyin-qingre Bufei-yishen method. J Emerg Tradit Chin Med 22: 134-135, 2013.

22. Xie DX. Clinical observation on Yu-pingfeng powder treating childhood coughing variant asthma. J Gannan Med Coll 32: 858859, 2012.

23. Zeng LY. Decoction of removing wind and sputum to relieve cough combined with western medicine in treatment of 60 cases of childhood coughing variant asthma. Clin J Chin Med 4: 22-23, 2012.

24. Peng XM. Clinical observation on childhood coughing variant asthma treated with Zhisou powder combined with Montelukast sodium tablets. Nei Mongol J Tradit Chin Med 3: 24-25, 2013.

25. Shuai MH, Guo CX. 65 cases of childhood coughing variant asthma treated by integrative medicine. Chin J Inform Tradit Chin Med 8: 64-65, 2011.

26. Zhu YX, Li JR. Clinical observation on childhood coughing variant asthma treated with Suhuang Zhike capsules combined with western medicine. Yunnan J Tradit Chin Med Mater Med 34: 2324, 2013.

27. Guo ZL, Chen GL. Clinical study on integrative medicine in the treatment of childhood coughing variant asthma. Mod Diag Treat 23: 1149-1150, 2012.

28. Li LD. Clinical observation on childhood coughing variant asthma treated by integrative medicine. Pract Clin J Integr Tradit Chin Western Med 13: 12-15, 2013.

29. Li K, Qin XH. Clinical observation on modified Jin-feicao powder combined with western medicine for 42 cases of childhood cough variant asthma. J Tradit Chi Med 55: 161-163, 2014.

\section{(C) 2016 The Japanese Society of Internal Medicine} http://www.naika.or.jp/imonline/index.html 